\title{
Teachers' Code Switching in an EFL Context: Why and When?
}

\author{
Mehdi Khonakdar ${ }^{1,2} \&$ Seyed Jalal Abdolmanafi-Rokni ${ }^{3 *}$ \\ ${ }^{1}$ Department of English Language Teaching, Gorgan Branch, Islamic Azad University, Gorgan, Iran \\ ${ }^{2}$ Department of English Language Teaching,Science and Research Branch, Islamic Azad University, \\ Gorgan, Iran \\ ${ }^{3}$ Department of English Language and Literature, Golestan University, Gorgan, Iran \\ *Seyed Jalal Abdolmanafi-Rokni, E-mail: j.abdolmanafi@gmail.com
}

\begin{abstract}
English is considered in Iran as a foreign language because Iranians enjoy this language in academic centers like schools and universities; therefore, the reasons of enjoying code switching in EFL classes can be considered as a study. This study was an attempt to investigate Iranian EFL teachers' reasons for code switching in Iranian EFL classes by sixty Iranian teachers who teach English as a foreign language. This article, although preliminary in nature, attempted to highlight and explain some of the functions of code-switching in the foreign language classroom. In short, this study has been made to investigate the trends of code-switching in Iranian EFL classrooms. A questionnaire was adopted from Gulzar (2010) to know the reasons and functions toward code switching in EFL classes. Nine most important functions toward code switching were asked of the teachers to state their functions based on the Likert scale. The results showed that teachers have different reasons and functions for code switching in EFL classes. The reasons why code switching is used dependson different reasons such as time, syllabus, and subject matter and so on.
\end{abstract}

\section{Keywords}

EFL, code switching, reason, Iranian teacher

\section{Introduction}

English in Iranian schools is taught as a foreign language by the teachers and students learn it. It can be said that nearly all schools choose English as a foreign language in Iran because this language is considered as an international language. Code switching is one of the ways which is applied in foreign language classrooms especially in Iran. It is stated that code-switching is a difficult, skilled linguistic methodology enjoyed by bilingual speakers to communicate necessary social understanding above and beyond the referential material of an utterance. This happens to comply with the interlocutor or to be different from him meaning that code switching is an outcome of language adaptation in different condition (Durano, 2009).

It is stated that code switching is one of the unavoidable outcomes of communication among different language diversity. Code switching has long existed as an outcome of language contact observed vastly 
especially in multicultural and multilingual and communities (Jingxia, 2010). In recent years EFL teachers enjoy different methods to teach English in the classes and they have their own reasons for code switching. Code-switching can be enjoyed in the class to assist learners overcome communication issues (Zabrodskaja, 2007). It is believed that English has been the common foreign language in the subjects of educational institutions like schools, universities, and different language schools and in foreign language learning (Abbasian \& Khajavi, 2011).

\subsection{Literature Review}

Code switching was defined by different scholars and researchers. It is stated that the ability of people who are able to enjoy to languages perfectly to choose between the languages in their linguistics abilities is called as code switching (Gulzar, 2010). Code switching is also enjoyed in EFL classes to state the points but it is important to know the reasons of code switching by EFL teachers; therefore, to know its reasons can be studied and it is considered to have some information on reasons for the code switchingby the EFL teachers.

\subsection{Why Teachers Code Switch}

There are different reasons that an Iranian teacher enjoys code switching in EFL classes. The use of mother tongue and foreign language in EFL classes has been studied for many years in different studies. There are different reasons why a teacher or an instructor switches his codes in language classrooms because the goals and purposes of the teachers to enjoy code switching in EFL classes are different; for example, they may enjoy code switching to translate, to clarify the points (Gulzar, 2010) and some other reasons.

English is taught in Iranian schools mostly as a foreign language. In the educational setting, code-switching has been found to be useful for informational and interpersonal purposes of communication. It can be said that the reason why an instructor selects code switching to approach or understand teaching or communicative aims or purposes is to adapt the linguistic real situation, the instructor's functions or the psychological motivations. In most of the classes Iranian teachers use Persian and English to teach lexical items and grammar points and help their learners to listen carefully to comprehend and understand both languages.

Sometimes to facilitate the way of achieving some important notes by learners, teachers apply code switching. Sometimes to gain the learners' attention, code switching is used in foreign languages classes by the teachers. Code switching is applied by the teachers in Iranian EFL classes to transfer the points between the target language and mother tongue.

Through code switching EFL teachers can help learners to have effective input of EFL points in EFL classes and also assist the learners to feel relax to decrease the anxiety and stress in the classes. Iranian EFL instructor's use of code switching is not a conscious selection in all the times and the instructors are not aware of the results of code switching process in EFL classes (Agneta \& Ana, 2010).

Code switching can also be used to make a difficult point easier for the learners in EFL classes because the learners are not familiar with all the EFL points. Sometimes the teacher paraphrases a sample 
material like grammar points to clarify the points that learners may have problems to understand. Sometimes code switching is used to translate the most important notes to the learners and by doing it the message is transferred by the teacher and is understood by the learners easier.

One of the most common types of code switching which is observed in EFL classes is topic switching. Sometimes teachers teach the material in the target language and then explain all these points in mother tongue, so the learners pay no attention to the discussion in the target language but focus all their attention to explanation in mother tongue. It was recommended that to emphasize and highlight important and key learning points, code switching can be a suitable tool for instruction as learners have difficulties in gaining the notes related to EFL points (Agneta \& Ana, 2010).

\subsection{Research Questions}

(1) Why do Iranian teachers in the EFL classrooms code-switch from target to native language?

(2) When do Iranian EFL teachers code-switch from Persian to English?

\section{Methodology}

\subsection{Research Design}

The research was done to investigate the Iranian EFL teachers' reasons toward code switching in EFL classes; therefore it was asked sixty Iranian EFL teachers' to state their ideas through a questionnaire. The questionnaire was distributed among them and the teachers stated their reasons toward code switching according to the written possible reasons of the questionnaire.

\subsection{Participants}

Sixty teachers who teach English as a foreign language were selected randomly as a sample of Iranian EFL teachers. The teachers were both male and female. They had different English degrees such as English Teaching, Literature, Translation, and General Linguistics. They teach English in Mazandaran's schools and universities in north of Iran. All of the teachers' native language was Farsi and English was their foreign language.

\subsection{Instrumentation}

The researchers enjoyed a questionnaire was adapted from Gulzar (2010) to do his study. The questionnaire had eleven possible reasons of code switching in Iranian EFL classes. The questionnaire was arranged based on the Likert scale. It was arranged from strongly agree to strongly disagree. Before doing the research the questionnaire was submitted to sample teachers in Mazandaran in North of Iran and the reliability of the questionnaire was determined $(\alpha=.76)$.

\subsection{Data Analysis}

The researcher of this study gathered the data through the above mentioned questionnaire. He then examined all the collected information to consider that whether they are enough to analysis. Then the gathered data were studied and the percentage of each part and item of the questionnaire was calculated by the researcher. Descriptive statistics was calculated in order to calculate the percentage of the items. 


\section{Results}

Through doing the present study by a questionnaire the reasons enjoying code switching were manifested and it was found that the reasons and also the time of the code switching are different and each EFL teacher may have his own reason to enjoy code switching in his EFL class and these reasons are not hundred percent the same among all the teachers. The results gathered through the questionnaire adapted from Gulzar (2010) were listed below to clarify the possible reasons of enjoying code switching by Iranian EFL teachers:

\section{Table 1. Distribution of the Code Switching Reasons in EFL Classes}

\begin{tabular}{ll}
\hline Variable & \% \\
\hline (1) Clarification & \\
Strongly disagree & 16.66 \\
Disagree & 8.33 \\
Not sure & 5 \\
Agree & 33.33 \\
Strongly agree & 36.66 \\
\hline
\end{tabular}

(2) Giving instructions effectively

Strongly disagree

Disagree

Not sure

Agree

(3) Translation

Strongly disagree

Disagree

Not sure

Agree

46.66

Strongly agree

41.66

(4) Socializing

Strongly disagree

Disagree

Not sure

Agree

Strongly agree 20

(5) Linguistics competence

Strongly disagree

Disagree 


$\begin{array}{lc}\text { Agree } & 30 \\ \text { Strongly agree } & 21.66\end{array}$

(6) Topic shift

Strongly disagree

3.33

Disagree

5

Not sure

8.33

Agree

33.33

Strongly agree

50

(7) Ease of expression

Strongly disagree

\section{5}

Disagree

6.66

Not sure

8.33

Agree

41.66

Strongly agree

38.33

(8) Emphasis

Strongly disagree

5

Disagree

13.33

Not sure

8.33

Agree

50

Strongly agree

23.33

(9) Checking understanding

Strongly disagree

8.33

Disagree

8.33

Not sure

16.66

Agree

36.66

Strongly agree

30

(10) Repetitive Functions

Strongly disagree

Disagree

5

Not sure

3.33

Agree

33.33

Strongly agree

45

(11) Create sense of belonging

Strongly disagree

16.66

Disagree

8.33

Not sure

5

Agree

28.33

Strongly agree

36.66 
The results displayed through the checklist adopted from Gulzar (2010) are listed below to clarify the possible reasons for enjoying code switching by Iranian EFL teachers: The first reason of the checklist considers the clarification. Table one in this study shows that 69.99 percent of the EFL teachers were positive toward teachers enjoying code switching for clarifying ideas and opinions. 24.99 percent of the teachers disagreed or strongly disagreed with this item and 5 percent of the teachers were not sure on this item. By looking at the data gathered on the first reasons, it can be said that code switching sometimes was enjoyed by the teachers who participated in this study to clarify the EFL points because the learner may have problems understanding the points in the target language. In the study done by Gulzar (2011), the percentages of strongly disagree and disagree, not sure, and agree and strongly agree were $6.9,5.9,87$ percent, respectively; Therefore, in this study most of the teachers agreed with this reason.

The second reason deals with giving instructions effectively. As the table shows, about 75 percent of the participants in this study strongly agreed and agreed while about 16.66 percent disagreed and strongly disagreed with this statement and 8.33 percent were not sure. To state the points and instruction of the material in EFL classes can be important for Iranian EFL teachers who participated in this study. Because half of the teachers who participated in this study strongly agreed with this reason and the percentage of the study done by Gulzar (2011) is as: 1.2 percent strongly disagreed, 9.9 percent disagreed, 7.9 percent were not sure, 62.1 percent agreed and 17.2 percent strongly agreed and others left this reason blank.

Question number three states that code switching is enjoyed in order to translate the EFL points. It is found that 41.66 percent of the teachers who participated in this study strongly agreed, 46.66 percent agreed, 3.33 percent strongly disagreed and 6.66 percent disagreed. To state this item, 1.66 percent of the teachers were not sure on the item. The data gathered on this reason showed that about half of the participants agreed with this reason and they believed that code switching can be enjoyed to translate the points and notes in EFL classes whereas the percentage of the study done by Gulzar (2011) is 1.7 percent strongly disagreed, 13.8 percent disagreed, 8.1 percent were not sure, 55.2 percent agreed, 18.7 percent strongly agreed and others left the reason blank.

The fourth possible reason stated in this questionnaire is for socializing. To answer this reason, 20 percent of participants strongly agreed, 25 percent agreed with this item, 29.99 percent of the teachers who stated their reason for code switching disagreed or strongly disagreed. About 25 percent of the teachers had no idea and ticked "not sure". This reason was enjoyed to consider the code switching for the socializing. The data showed that the teachers who participated in this study were not familiar with the code switching enough. The data in study done by Gulzar (2011) showed that 3 percent strongly disagreed, 11.6 percent disagreed, 14.3 percent were uncertain, 55.2 percent agreed, 14.3 percent strongly disagreed and others left it blank. In this study most of the teachers agreed with this reason and enjoyed code switching for this reason.

About 21.66 percent of the participants strongly agreed with item 5, 30 percent of the teachers agreed 
and also 20 percent of the teachers disagreed. The percent for strongly disagreed toward item 5 was 20 and 8.33 percent were not sure and had no idea. About half of the teachers who participated in this study believed that code switching can be enjoyed to have linguistic competence and they enjoyed code switching for this reason in their classes whereas in the study done by Gulzar (2011) 6.2 percent strongly disagreed, 23.4 percent disagreed, 18 percent were not sure, 39.9 percent agreed, 10.1 percent strongly agreed and other participants left this reason blank.

3.33 percent of the teachers strongly disagreed on the sixth reason of code switching, 5 percent of the participants in this study disagreed and about 83.33 percent of the teachers agreed or strongly agreed on this item. About 8.33 percent of Iranian teachers who participated in the study had no idea on this item. The EFL topic is a challenging consideration based on the ideas of teachers who participated in this study because nearly most of the teachers agreed or strongly agreed with this reason. The findings in Gulzar (2011) showed that 3.4 percent strongly disagreed, 16.7 percent disagreed, and 19.2 percent were not sure, 58.1 percent of them agreed or strongly agreed. It shows that these teachers had the same idea with the teachers who participated in the current study.

The results show that 38.33 percent of the teachers who took part in this study strongly agreed on seventh item. The percentage of teachers who agreed on this item was 41.66. To consider the percentage of teachers who strongly disagreed and disagreed on the item, it can be said that 5 , and 6.66 and 8.33 percent of the teachers had no idea on the item. This result confirms that when sometimes the Iranian teachers enjoy code switching, they state their expression easily for the learners. The results of the study done by Gulzar (2011) showed that the percentages of the participants' ideas were 2 percent for strongly disagree, 9.6 percent for disagree, 7.1 percent not sure, 63.3 percent of them agree, and others disagree or left the items without idea.

The eighth possible reason stated in the questionnaire said that a teacher may enjoy code switching to emphasize the EFL points. This reason of code switching manifested that most of the Iranian teachers who participated in this study enjoyed code switching to emphasize and highlight the EFL points for the learners in EFL classes. The teachers state their attitudes toward this reason as follows: 5 percent of the teachers strongly disagreed, 13.33 percent of the teachers disagreed, 23.33 percent of them strongly agreed and 50 percent of the teachers agreed. Some teachers had no idea and the percentage of this alternative was 8.33. This reason for the participants of Gulzar (2011) manifested the data that 16.3 percent strongly disagree and disagree, 14 percent not sure, 66.9 percent agree or strongly agree that was the highest percentage of this reason and others left this reason blank and did not state their ideas. It is always challenging to know whether a learner understands the point in EFL classes or not which means a learner never stated his real request in the class and an EFL Iranian teacher may have problem to check the understanding of the learners. Therefore, he may enjoy code switching to check the understanding of the learners. The percentage of the participants stating their points was as follows: Item 9 deals with checking understanding for which about 9 percent of the teachers strongly disagreed and 8.33 percent disagreed on this reason. Some teachers believed that code switching can be a safe 
way to have students' answers; therefore, 30 percent of the teachers strongly agreed and 36.66 percent of the teachers agreed. About 16.66 percent students had no special idea on this item. The data of study for Gulzar (2011) is as follows: Strongly disagree and disagree: 4.7 percent; agree and strongly agree: 71.7 and others are whether not sure or left it blank.

When it came to tenth reason about whether teachers enjoy code-switching for repetitive function, 78.33 percent of the sample agreed or strongly agreed with this opinion on the tenth item, whereas 5 percent disagreed, and 13.33 percent of the teachers strongly disagreed and 3.33 were uncertain. In the study done by Gulzar (2011), more than half of the teachers agreed and strongly agreed with this reason.

In reply to the last reason, creating a sense of belonging, 16.66 percent of the responders strongly disagreed and 8.33 percent of the teachers disagreed on the item. Some teachers believed in this item and stated that they strongly agreed and the percentage of this item was 36.66. About 28.33 percent of the teachers ticked agree and others were not sure about this item. The teachers who participated in the current study believed that EFL teachers should try to create an atmosphere in the class that the learners have a sense of belonging. In the study done by Gulzar (2011), the data were as follows: 1.7 percent strongly disagreed, 8.6 percent disagree, 13.3 percent not sure, 57.1 percent agree, 15.3 percent strongly agree and others had no ideas.

As it is seen in the results of the checklist answered by the Iranian EFL teachers who participated in this study, it can be said that most of the teachers enjoyed code switching to give the instruction effectively and shift the topic of the class in EFL classes whereas in the study done by Gulzar (2010) they stated their expression easily. Most of the teachers who participated in this study did not enjoy code switching to translate the points whereas in the study done by Gulzar (2010) most of the teachers did not enjoy code switching to give the instructions effectively.

\section{Conclusion and Pedagogical Implications}

By looking at the data gathered in the current study, it can be said that code switching can be enjoyed by the EFL teachers to provide the students' goals when the target language cannot be a unique way of teaching EFL points; therefore code switching can be suggested or recommended to state the points in EFL classes.

This study revealed some possible reasons to enjoy code switching and it was manifested that which one is enjoyed most of the time in EFL classes by the teachers who participate in this study and which ones are enjoyed by these teachers. By considering the points and data collected in this study, it can be said that code switching can be as a facilitator in some situations such as checking the learners' understanding toward the EFL points and also the teachers can enjoy code switching to translate some challenging points and structures through code switching; but it should be considered that code switching is not always feasible in EFL classes and it may be harmful for transferring the points.

Considering the reasons of code switching by Iranian EFL teachers can be as an introduction to do 
other related topics therefore this study can be important for all who work with teaching and also topics of teaching. Reasons and also the time of code switching were examined because the researcher believe that to enjoy code switching by the Iranian EFL teachers is a challenging method of teaching EFL and some banned code switching and also ignore the importance of code switching in some occasions therefore it was hoped that doing the present research and study may help the individuals who consider and also study English as a foreign language.

\section{References}

Abdul, S. A., \& Rahmani, S. E. (2012). Code switching as a medium of instruction in an EFL classroom. Theory and Practice in Language Studies, 2(11), 2219-2225.

Agneta, A., \& Ana, B. (2010). A study of teachers' code switching in six Swedish EFL classrooms (pp. $1-43)$.

Ahmad, B., \& Jusoff, K. (2009). Teachers' code-switching in classroom instructions for low English proficient learners. English Language Teaching, 2(2), 23-44.

Ajmal, G. M. (2010). Code switching, awareness about its utility in bilingual classrooms. Bulletin of Education and Research, 32(2), 23-44.

Alcnauerová, Z. (2013). Code-switching and code-mixing as persuasive strategies in advertising (Unpublished bachelor's thesis). Masaryk University.

Asali, S. (2011). Attitudes of Arab American speakers in the USA towards English-Arabic code switching (Unpublished master's thesis). Middle East University.

Auer, P. (1998). From code-switching via language mixing to fused lects: Toward a dynamic typology of bilingual speech. Retrieved November 11, 2014, from http://www.ling.uni-konstanz.de/ home/couperku/inlist-index.html

Ayeomoni, M. (2006). Code switching and code mixing: Style of language use in childhood in your speech community. Nodric Journal of African studies, 15(1), 12-24.

Chaiwichian, U. (2007). Thai-English code switching of students in the mini English program (Unpublished master's thesis). Suranaree University of Technology.

Chen-On, T. D., \& Ting, S. (2011). Researching code switching in teacher classroom discourse: Questioning the sufficiency of informant reports. The International Journal-Language Society and Culture. Retrieved November 11, 2014, from http://www.educ.utas.edu.au/users/ tle/JOURNAL

Dhaouadi, H. (1993). Educators' and parents' attitudes towards code switching by Arab bilinguals: Pedagogical implications (Unpublished master's thesis). University of Sharjah.

Durano, F. (2009). Attitudes towards English and Fil-English code-switching amongst high school students in Ormoc city, Philippines (pp. 1-49).

Gulzar, M. (2010). Classroom discourse in bilingual context: Effects of code switching on language learning in Pakistani TEFL classroom (Unpublished doctoral thesis). National University of 
modern language Islamabad.

Hamzehlou, M. S., Abdul, S. A. \& Rahmani, S. E. (2012). Code switching as a medium of instruction in an EFL classroom. Theory and Practice in Language Studies, 2(11), 2219-2225.

Iqbal, L. (2011). Linguistic features of code-switching: A study of Urdu/English bilingual teachers' classroom interactions. International Journal of Humanities and Social Science, 1(14), 188-194.

Jakobsson, C., \& Rydén, H. (2010). A Study of code switching in four Swedish EFLclassrooms. Retrieved November 11, 2014, from http://dspace.mah.se/bitstream/.../astudyofcodeswitching.pdf

Jalal, R. (2010). A suggestion to use code switching as an L1 resource in the students' written work: A pedagogical strategy (Unpublished master's thesis). Colorado State University.

Jegede, O. (2012). Roles of code switching in multilingual public primary schools in Ile-Ife, Nigeria. American Journal of Linguistics, 1(3), 40-46.

Jingxia, L. (2010). Teachers' code-switching to the L1 in EFL classroom. The Open Applied Linguistics Journal, 3(10), 10-23.

Johansson, S. (2013). Code switching in the English classroom, what teachers do and what their students wish they did. Faculty of Arts and Social Sciences, 1-23.

Kamyab, S. H. (n.d.). An overview of the education system of Islamic Republic of Iran.

Khajavi, K., \& Abbasian, R. (2011). English language teaching, national identity and globalization in Iran, the case of public schools. International Journal of Humanities and Social Science, 1(10), 181-186.

Lee, W. (2010). Code switching as a communicative strategy in a Korean heritage language classroom (Unpublished master's thesis). University of San Diego.

Lin, A. (1996). Bilingualism or linguistic segregation? Symbolic domination, resistance and code-switching in Hong Kong schools. Linguistics and Education, 8, 9-84.

Mahootian, S. (2006). Code switching and mixing. Language and Linguistics, 2, 511-527.

Martin, P. (1999). Bilingual unpacking of monolingual texts in two primary classrooms in Brunei Darussalam. Language and Education, 13(1), 38-58.

Mojtahedzadeh, M., \& Mojtahedzadeh, R. (2012). The role of English language teaching and learning in Iran. International Journal for Quality Research, 6(2), 125-130.

Pennington, M. (1995). Pattern and variation in use of two languages in the Hong Kong secondary English class. RELC Journal, 80-105.

Redinger, D. (2010). Language attitudes and code-switching behavior in a multilingual educational context: The case of Luxembourg (Unpublished doctoral thesis). The University of York.

Reyes, I. (2001). The Development of grammatical and communicative competence in bilingual Spanish speakers (Unpublished doctoral dissertation). University of California, Berkeley.

Rezaeian, F. (2009). Structural and social aspects of code switching among Iranian/Canadian bilinguals (Unpublished master's thesis). Esfahan University.

Rezvani, E., \& Eslami, R. A. (2011). Code switching in Iranian elementary EFL classrooms. English 
language teaching, 4(1), 18-25.

Shin, J. (2010). The functions of code switching in a Korean Sunday school. Indiana University, Bloomington, 7(1), 91-116.

Shogren, J. (2011). Analysis of code switching and code mixing among bilingual children: Two case studies of Serbian-English language interaction (Unpublished master's thesis). Wichita State University.

Tabaku, E. (2014). Code switching: Beliefs and attitudes of Albanian pre service English teachers. Journal of educational and social research, 4(2), 384-389.

Uys, D. (2010). The functions of teachers' code switching in multilingual and multicultural high school classrooms in the Siyanda district of the Northern Cape Province (Unpublished master's thesis). Intercultural Communication at Stellenbosch University.

Velásquez, M. C. (2010). Language and identity: Bilingual code switching in Spanish-English interviews (Unpublished master's thesis). University of Toronto.

Yao, M. (2011). On attitudes to teachers' code-switching in EFL classes. World journal of English language, 1(1), 9-28.

Yletyinen, H. (2004). The function of code switching in EFL classroom discourse (Unpublished master's thesis). University of JYVÄSKYLÄ.

Youkhana, S. (2010). Code switching in the foreign language classroom (pp. 1-41).

Zabrodskaja, A. (2007). Russian-Estonian code switching in the university. Arizona Working Papers in SLA \& Teaching, 14, 123-129. 